\title{
EL COVID-19 Y SU IMPACTO EN EL CONTRATO DE SEGUROS UNA VISIÓN DESDE EL DERECHO DE SEGUROS
}

\section{COVID-19 AND THE IMPACT ON THE INSURANCE CONTRACT A VISION FROM INSURANCE LAW}

\author{
ANDREA SIGNORINO BARBAT* \\ Fecha de recepción: 30 de abril 2020 \\ Fecha de aceptación 15 mayo 2019 \\ Disponible en línea: 30 de junio 2020
}

Para citar este artículo/To cite this article

Signorino Barbat, Andrea. El COVID-19 y su impacto en el contrato de seguros. Una visión desde el derecho de seguros, 52 Rev.Ibero-Latinoam.Seguros, 53-68 (2020). https://doi. org/10.11144/Javeriana.ris52.cics

doi: 10.11144/Javeriana.ris52.cics

\footnotetext{
* Doctora en Derecho y Ciencias Sociales, Traductora Pública, Universidad de la República Oriental del Uruguay. Postgrados en Gerencia, Habilidades gerenciales y Dirección de personas, Universidades ORT, EDU y Católica del Uruguay. Secretaria General de AIDA World (Association Internationale du Droit des Assurances), Secretaria académica internacional AIDA-Uruguay, Presidente Grupo internacional Nuevas Tecnologías, Prevención y Seguros en AIDA, Vicepresidente Grupo internacional Principios generales del contrato de seguros en AIDA- Miembro Comisión Directiva de la Asociación uruguaya de derecho marítimo. Profesora de grado y postgrado en seguros en Argentina, Brasil, Colombia y Uruguay. Directora académica en Universidad de Montevideo. andreasignorino@gmail.com.uy - http://www.andreasignorino. com.uy - www.andreasignorino.com.uy
} 


\section{RESUMEN}

El impacto de la aparición del nuevo virus, el COVID-19, convertido en una pandemia, y su influencia en los contratos privados, está hoy siendo un tema de intenso debate. De este contexto, no escapa el seguro que cobra una importancia esencial, pues detrás de toda actividad económica, existe, o debería existir, el seguro como elemento que respalde dicha actividad, que permita al comerciante desarrollar su negocio con visión de prevención y sea útil a todas las personas como respaldo ante los infortunios.

El contrato de seguros se basa en un equilibro que excede el mero equilibrio contractual entre las prestaciones de las partes, pues su desequilibrio produce consecuencias que afectan no sólo a las partes en el contrato, sino que puede llegar a afectar a la mutualidad de asegurados. Si ese desequilibrio permanece sin ser solucionado, si no se recompone el equilibrio, se pone en peligro la solvencia de la empresa de seguros y por lo tanto a todo el sistema asegurador nacional e incluso internacional, cual efecto dominó.

Ante esta realidad técnico-jurídica del seguro, un factor imprevisto como la aparición de la pandemia del COVID-19, puede alterar y mucho, el equilibrio contractual.

En el presente artículo buscaremos recurrir a los institutos propios del seguro como ser los riesgos no cubiertos, el agravamiento y la disminución del riesgo, para tratar de buscar respuestas en la esfera del derecho de seguros.

Palabras claves: Pandemia, seguros, riesgos, agravamiento, disminución. 


\begin{abstract}
The impact of the appearance of the new virus, COVID-19, turned into a pandemic, and its influence on private contracts, is today being a subject of intense debate. In this context, insurance play an important role, because behind all economic activity, there is, or should be, insurance as an element that supports this activity, which allows the merchant to develop his business with a vision of prevention and to help all people as backup vis à vis the risks.

The insurance contract is based on a balance that exceeds the normal contractual balance between the parties duties and rights, since its imbalance produces consequences that affect not only the parties but may even affect the mutual fund of the policyholders. If that imbalance remains unresolved, if the balance is not restored, the solvency of the insurance company and therefore the entire national and even international insurance system, could be in danger.

Faced with this technical-legal reality of insurance, an unforeseen factor such as the appearance of the COVID-19 pandemic, can greatly alter the contractual balance.

In this article we will seek to resort to the insurance institutes such as uncovered risks, the aggravation and reduction of risk, to try to find answers within the insurance law.
\end{abstract}

Key words: Pandemic, insurance, risks, aggravation, reduction.

\title{
SUMARIO
}

1. Introducción; 2. Posibles enfoques; 3. Los Institutos propios del seguro: riesgo no cubiertos, agravación y disminución de riesgos; 4. La teoría de la imprevisión y la fuerza mayor; 5. Concluyendo. Bibliografía. 


\section{INTRODUCCIÓN}

Mucho se está hablando por estos días, sobre el impacto de la aparición del nuevo virus, el COVID-19, convertido no solo en una epidemia, sino en una pandemia, por lo tanto, de alcance mundial.

Ante esta internacionalización del mentado coronavirus, la actividad de la humanidad, tanto económica como social, se ha visto absolutamente alterada, como tal vez lo haya sido - pues no podemos comparar, no la vivimos como ahora si nos ocurre- la pandemia de gripe española de 1918, o como pudo resultar alterada luego de las Guerras mundiales, la primera que justamente termina en 1918 y la segunda en 1945.

Ahora bien, muy distintos eran los temperamentos humanos y la vida en esas épocas, donde las comodidades e inmediateces de la vida actual, o mejor dicho anterior al coronavirus, no existían y donde el sentido del sacrificio y la capacidad de recuperación y resiliencia eran muy diferentes, si bien es dado señalar que los avances de la tecnología y de la ciencia nos hacen vislumbrar, con optimismo, una salida tal vez menos dolorosa que las entonces vivenciadas por nuestros antepasados.

En este contexto, es claro que el seguro cobra una importancia esencial, pues detrás de toda actividad económica, existe, o debería existir, el seguro como elemento que respalde dicha actividad, que permita al comerciante desarrollar su negocio con visión de prevención y sea útil a todas las personas como respaldo ante los infortunios.

Sumado a ello, el seguro es un contrato global, en el sentido que sus efectos trascienden fronteras no solo porque las empresas aseguradoras en su operativa utilizan el respaldo internacional del reaseguro, sino porque el propio seguro se basa en fundamentos técnicos de estudios estadísticos de riesgos, con criterio de homogeneidad cualitativa -referido a un mismo riesgo- y cuantitativa - en una determinada población- que suelen ser internacionales. La aplicación de la ley de los grandes números, le permite arribar a conclusiones estadístico-actuariales de frecuencia siniestral y de valor del riesgo como componente de la prima neta, que le permiten en definitiva efectuar una correcta distribución de sus riesgos así estudiados y una adecuada definición del premio, que, por la asunción de dichos riesgos, debe recibir.

Dichos riesgos y premios se distribuyen no solo en una cartera de seguros sino en todo el sistema de seguros de un país y de fuera de este también, si es el caso de aseguradoras que conforman grupos económicos internacionales. Todos en seguros somos socios, compartimos solidariamente nuestros riesgos y aportamos al fondo de premios que administra el asegurador, pertenecemos a la mutualidad de asegurados que es la que justifica el interés general tutelado por leyes imperativas de seguros, y ameritan el contralor estatal de la actividad de seguros.

El contrato de seguros pues, se basa en un equilibro que excede el mero equilibrio contractual entre las prestaciones de las partes, pues su desequilibrio produce consecuencias que afectan no sólo a las partes en el contrato, sino que puede llegar a afectar a la mutualidad de asegurados. Si ese desequilibrio permanece sin ser solucionado, si no se recompone el equilibrio, se pone en peligro la solvencia de la empresa de 
seguros y por lo tanto a todo el sistema asegurador nacional e incluso internacional, cual efecto dominó.

Ante esta realidad técnico-jurídica del seguro, un factor imprevisto como la aparición de la pandemia del COVID-19, puede alterar y mucho el equilibrio contractual.

\section{POSIBLES ENFOQUES}

En todo este tiempo desde que el coronavirus llegó a nuestras vidas, he estado leyendo y escuchando muchas opiniones sobre cómo afecta a los contratos la aparición de la pandemia. Con el preaviso de que entiendo que no existe suficiente perspectiva histórica como para arribar a soluciones ni opiniones definitivas, creo que varios de dichos enfoques no están teniendo en cuenta la especificidad que tiene el contrato de seguros en especial por las bases técnicas antedichas.

Entiendo que se han buscado soluciones en los institutos clásicos del derecho privado como ser la teoría de la imprevisión o la fuerza mayor, pero se han minimizado las soluciones que son propias del contrato de seguros. Comprendo, claro que sí, que las soluciones del derecho de fondo son una herramienta; solo reivindico que tengamos presentes los institutos propios del contrato de seguros, como ser los riesgos no cubiertos y el agravamiento y disminución del riesgo.

Es decir, estos institutos nos podrán aportar algunas soluciones o respuestas, y otras no, pues es claro que el contrato de seguros y las leyes imperativas que lo regulan, establecen un mínimo de cobertura y seguridad jurídica para el asegurado-consumidor, en un contrato por norma de adhesión, que no se pueden vulnerar mediante limitaciones del riesgo contractuales abusivas ni esgrimiendo argumentos sin el debido sustento técnico y legal. En ese caso, recurrir al derecho de fondo puede ser la solución.

Ahora bien, lo que reivindico es que, sin perjuicio de recurrir a ese derecho de fondo, no nos olvidemos del derecho de seguros. Hagamos también el ejercicio a la luz de los institutos propios de este último.

Veamos pues sucintamente, los distintos enfoques.

\section{LA TEORÍA DE LA IMPREVISIÓN Y LA FUERZA MAYOR ${ }^{1}$}

Sabido es que los contratos son celebrados con la presunción de que serán rigurosamente cumplidos, observándose los términos originariamente previstos. Es la aplicación de la clásica cláusula pacta sunt servanda por la cual los contratos deben ser cumplidos.

Esta cláusula llevada hasta las últimas consecuencias, muchas veces termina en una situación de injusticia si en el transcurso del tiempo, sobre todo en contratos de eje-

${ }^{1}$ Gamarra Jorge, "Imprevisión y equivalencia contractual", Cuadernos del Anuario de Derecho Civil Uruguayo, Fundación de Cultura Universitaria, Montevideo, 2006. 
cución continuada como lo es el contrato de seguros, sobreviene una significativa alteración de aquellas condiciones primarias que llevaron a las partes a contratar, alterándose la base del negocio.

Estas alteraciones, normalmente están vinculadas a una fuerza ineludible de circunstancias externas, que llevan a un grave desequilibrio y carencia de equidad en la relación jurídica respectiva, produciendo el enriquecimiento excesivo de uno de los contratantes a costas del otro.

Las nuevas funciones sociales de los contratos han llevado a que modernamente el principio general derivado de la citada cláusula pacta sunt servanda se haya atenuado sensiblemente. Principalmente en los países occidentales, se ha admitido una revisión de las condiciones de los contratos, en esencia mediante la intervención judicial, invocada por el contratante en situación de desventaja.

Esta posibilidad de intervención judicial en el contrato solamente ocurrirá cuando un elemento sorpresivo, surja en el curso de la ejecución del mismo, colocando, en extrema dificultad a uno de los contratantes. O sea, ocasionando una excesiva onerosidad, superando el límite razonable, lo que la doctrina alemana denomina opfergrenze ${ }^{2}$.

En relación al origen histórico, ya en la Edad Media se admitió la posibilidad de alteración del contrato si las condiciones originarias, sobre las cuales se fundó la voluntad de las partes, fuesen substancialmente modificadas, a través de la consagración de la cláusula "contractus qui habent tractum sucessiun et dependetian de futuro rebus suc stantibus intelligentur", difundida luego en forma resumida como "rebus sic stantibus" -"estando así las cosas"- cláusula considerada implícita en todo contrato de ejecución continuada o de tracto sucesivo, como lo es el contrato de seguros.

Esta cláusula, adquirió gran vigor con posterioridad a la Primera guerra mundial (19141918), en virtud del desequilibrio causado en los contratos a largo plazo, quedando conocida a partir de entonces, y en la actualidad, como "Teoría de la Imprevisión”3.

En efecto, con el estallido de la Primera guerra mundial tuvieron lugar situaciones contractuales insostenibles, especialmente en Europa. Las mismas ocasionaron una onerosidad excesiva para una de las partes contratantes, desequilibrios en la vida cotidiana, fracaso de previsiones en el comercio y actividad empresarial, así como mutaciones imprevistas tanto en la economía nacional como internacional.

Fue entonces necesario, considerar y valorar una variedad de controversias y situaciones, en las que se encontraban personas, empresas, asociaciones, y segmentos sociales económicamente activos, sorprendidos por las circunstancias extraordinarias, y por ello, reducidos a la imposibilidad o extrema dificultad de cumplir satisfactoriamente con las obligaciones originalmente asumidas.

\footnotetext{
2 DuRÁN MÉNDEZ, S. Imprevisión en contratos aleatorios: una revisión analítica a la teoría de la imprevisión bajo el artículo 868 del Código de Comercio. Revista de Derecho Privado, (55). Universidad de los Andes (Colombia). http://dx.doi.org/10.15425/redepriv.55.2016.04, 2016.

3 Fernández, De Almeida, Tesis doctoral Universidad de Salamanca “Alteración de las circunstancias y Revisión contractual", 2011.
} 
Los juristas de la posguerra, invocaron y perfeccionaron la antigua figura de la cláusula rebus sic stantibus, ahora llamada "Teoría de la Imprevisión", hoy fortalecida por los conceptos más amplios y abarcadores derivados de la "Teoría de la base del negocio Jurídico", que dio oportunidad para el surgimiento en el actual Código Civil Alemán, al denominado "Derecho de la perturbación de las prestaciones"4-5.

La denominada Teoría de la Imprevisión, por lo tanto, es fruto concreto de los principios de buena fe y de la siempre necesaria equidad contractual, buscando en última instancia, el respeto de la intención real de las partes.

Pero la Teoría de la Imprevisión, es un instituto lleno de dificultades, tanto en la práctica, como en la teoría, especialmente a nivel de doctrina y jurisprudencia. Existen distintas opiniones sobre su aplicación y cabida, en el difícil contexto de las demandas judiciales, con todos los problemas ya conocidos.

Respecto a la causa extraña, caso fortuito y fuerza mayor nuestra Código de Comercio establece ${ }^{6}$ :

“Art. 219. El deudor es condenado al resarcimiento de daños y perjuicios, sea en razón de la falta de cumplimiento de la obligación, o de la demora de la ejecución, aunque no haya mala fe de su parte, siempre que no justifique que la falta de cumplimiento proviene de causa extraña que no le es imputable.

Art. 220. No se deben daños y perjuicios, cuando el deudor no ha podido dar o hacer la cosa a que estaba obligado, o ha hecho lo que le estaba prohibido, cediendo a fuerza mayor, o por caso fortuito.

No se entienden comprendidos en la regla antecedente, los casos siguientes:

1. Si alguna de las partes ha tomado sobre sí especialmente los casos fortuitos, o la fuerza mayor.

2. Si el caso fortuito ha sido precedido de alguna culpa suya, sin la cual no habría tenido lugar la pérdida o inejecución.

3. Si el deudor había caído en mora antes de realizarse el caso fortuito, no comprendiéndose en esta excepción el caso en que la cosa habría perecido del mismo modo, en manos del acreedor"

\footnotetext{
4 Fernández, De Almeida, op. cit.

5 En Uruguay se podría sumar el análisis de la Teoría de los Riesgos que plantea la suerte de las obligaciones de las partes cuando la cosa que es objeto del contrato se pierde a consecuencia de un caso fortuito. Esta teoría supone que nos encontramos ante un contrato bilateral, y que al menos una de las obligaciones de las partes es de dar. Pero si la obligación es dineraria, como podría ser la prestación del asegurado del pago del premio ¿podemos afirmar que la pandemia como causa extraña hace cesar su obligación de pago? Entiendo que esta Teoría no resulta aplicable al caso analizado.

${ }^{6}$ El Código Civil uruguayo también se refiere a la causa extraña, caso fortuito y fuerza mayor en sus artículos 1342 y 1343, pero siendo el contrato de seguros un acto de comercio, regido por el derecho comercial, cabe referirse en especial al Código de Comercio.

7 Código de Comercio de la República Oriental del Uruguay.
} 
Como se puede apreciar consagra tres causales eximentes de los daños y perjuicios a cargo del deudor de obligaciones de dar o hacer: causa extraña no imputable, caso fortuito y fuerza mayor que la norma no define.

Así pues, ante el nuevo virus se invoca la Teoría de la imprevisión y la fuerza mayor, en los términos antes vistos.

Se afirma que el COVID-19 es un evento novedoso, imprevisible e impredecible, que puede justificar que el asegurador no cumpla con las obligaciones a su cargo, es decir el pago de indemnizaciones o prestaciones. Es un evento que tornaría las prestaciones del asegurador excesivamente onerosas, en su perjuicio.

Pero no debemos olvidar que el negocio del asegurador es justamente asumir riesgos ajenos y por lo tanto la mentada teoría debe relativizarse o analizarse a la luz de las especificidades del contrato de seguros, pues el no cumplimiento del asegurador genera un perjuicio excesivo en este caso, para la otra parte, el asegurado.

En realidad, si el riesgo de pandemia es un riesgo no cubierto el asegurador directamente no cubriría por esta previsión contractual excluyente.

Distinto es que las autoridades obliguen a los aseguradores a asumir riesgos que no tiene previstos en sus contratos o que tiene excluidos. En este caso la imprevisibilidad será, si, un argumento pues es claro que el desequilibrio contractual en contra del asegurador se produce por razones ajenas a su voluntad, y debe asumir riesgos por los que no ha recibido contraprestación.

También he visto afirmar que en realidad la imprevisión que crea una excesiva onerosidad para el asegurador radica en que hay autoridades que han decidido cerrar los comercios, no permitir su actividad y entonces ante los reclamos de algunas coberturas como ser de interrupción de negocio, pérdida de ganancias, el asegurador puede esgrimir la no cobertura. No pretendo aquí, pues excede el alcance de este artículo, ingresar en el tema de si este tipo de cobertura para activarse necesita o no de daño material y si el virus es un daño de este tipo, pero es claro que, en concreto para esta cobertura, sería un problema adicional a analizar.

Creo que aquí lo que existe es un hecho del príncipe o incluso una causa extraña no imputable o fuerza mayor, con lo cual el deudor de la obligación, el asegurador podría exonerarse. Obviamente, el análisis caso a caso será necesario pues por ejemplo en algunos países el Gobierno ha "sugerido" el cierre, pero no lo ha obligado.

Ahora bien, ¿por qué la Teoría de la imprevisión o la fuerza mayor debería ser útil solamente para el asegurador? Los asegurados también podrían esgrimir que el nuevo virus es una situación imprevisible e impredecible que hace que sus compromisos de pago de premios se tornen excesivamente onerosos, en especial ante la situación de cierre de comercios, inactividad forzada con el consecuente desempleo o cobro parcial de sueldos - a través del sistema de seguridad social por desempleo o enfermedad-o bien el pago de premios por coberturas que por el COVID-19 se han tornado innecesarias como puede ser los seguros automotores - de daño propio o de respon- 
sabilidad civil- para vehículos a los que no se les permite circular o que no puede ser utilizados para el trabajo.

Destaco pues la confusión en los enfoques, sobre todo generado en que la teoría de la imprevisión enfrenta las dificultades propias de las interpretaciones doctrinarias y jurisprudenciales antedichas, sobre su definición y alcance, al igual que los conceptos de causa extraña y fuerza mayor.

Ante estas dificultades, reivindico la necesidad de, al menos, analizar las soluciones propias del especial contrato de seguros, que se fundan en sus bases técnicas antes mencionadas.

\section{LOS INSTITUTOS PROPIOS DEL CONTRATO DE SEGURO: RIESGOS NO CUBIERTOS, AGRAVAMIENTO Y DISMINUCIÓN DEL RIESGO}

En primer lugar, como he dicho si el riesgo de pandemia, como riesgo catastrófico, es un riesgo no cubierto en el contrato de seguros, esto debe ser respetado como tal y no obligarse al asegurador a asumirlos. Si el no cubierto es el riesgo de epidemia, entiendo que la pandemia podría quedar asimismo excluida pues la diferencia entre ambas conceptualizaciones radica en el alcance territorial, no en la gravedad o carácter extraordinario del riesgo que es lo que justifica la exclusión.

Lo mismo si el riesgo directamente no ha sido asumido por el asegurador, no se puede obligar a éste a cubrirlos.

Es claro que, en caso contrario, se pone en peligro a la mutualidad de asegurados pues se hace asumir al asegurador riesgos por los cuales no ha recibido contraprestación, premios, pues no ha considerado estos riesgos dentro de sus estudios técnicos-actuariales.

Ahora bien, esto para contratos vigentes.

Para futuros contratos, el asegurador debería adecuar el premio al riesgo asumido, lo cual no es, evidentemente, sencillo pues la pandemia no es de fácil dimensionamiento, y riesgos que no son medibles, no son tasables, no pueden ser dimensionados como para ser riesgos asegurables.

Si a esto le sumamos la poca distancia histórica como para poder sacar conclusiones estadísticas, llegaremos a concluir que los futuros contratos si quieren cubrir las consecuencias del COVID-19, ya sea en las actividades económicas, interrupción de negocios, pérdidas de ganancias, etc., ya sea en las personas, enfermedades profesionales, seguros de salud o incluso seguros de desempleo o pensiones, o bien serán excesivamente onerosos, o bien serán riesgos asumidos sin la debida base técnica y por lo tanto con amenazas claras para la solvencia del asegurador ante la incertidumbre de la frecuencia e intensidad siniestral.

Ante esto creo que otro análisis necesario, es el del instituto del agravamiento del riesgo, así como su contracara, la disminución del riesgo. 
Nuestra Ley de seguros $\mathrm{N}^{\circ} 19.678$ vigente desde el 19 de noviembre de 2018, presta especial interés al agravamiento -la ley no utiliza el clásico término agravación- del riesgo y su relación con el siniestro, tanto en seguros de daño como de personas.

El Art. 18 define el agravamiento del riesgo como toda circunstancia que si hubiese existido al tiempo de la celebración del contrato lo hubiere impedido o modificado sus condiciones, obligando al tomador a las correspondientes comunicaciones al asegurador, antes del agravamiento si es por hecho propio, e inmediatamente de conocerlo si es por hecho de tercero.

El Art. 19 determina que, no existiendo siniestro, si la agravación del riesgo se debe a hecho -propio- del tomador, asegurado o de quienes lo representen, la cobertura queda suspendida desde el momento en que la agravación se produce.

Si la agravación se debe al hecho de tercero, la cobertura queda suspendida desde el momento en que es conocida por el asegurado, o habiendo tomado conocimiento el asegurador, desde el momento en que notifica al asegurado tal circunstancia.

En ambos casos dentro de los quince días corridos desde que al asegurador le fue declarado el agravamiento del riesgo, el asegurador puede rescindir el contrato con derecho a los premios corridos hasta el momento de la rescisión, o acordar modificarlo, es decir, ajustarlo al riesgo resultante del agravamiento.

Si nada de esto sucede, vencido el plazo, el contrato se mantendrá en las condiciones pactadas inicialmente.

Es importante pues, que el asegurador recomponga el equilibrio contractual que se altera con el agravamiento, pues si no lo hace estará cubriendo riesgos sin la debida contraprestación, lo cual, en vista a los aspectos técnicos del seguro, puede hacer peligrar a la mutualidad de asegurados en virtud de la distribución de riesgos y de premios que opera en ella.

Este Art. 19 no aplica a los seguros sobre personas que se rigen por su propia disposición que establece que solo se debe denunciar la agravación del riesgo que obedezca a motivos previstos en la póliza.

En estos seguros, de acuerdo al Art. 102, los cambios de profesión o de actividad autorizan la rescisión cuando agravan el riesgo de modo tal que, de existir a la época de la celebración, el asegurador no hubiera concluido el contrato de acuerdo con los usos y costumbres comerciales. Si hubiese existido ese cambio al tiempo de la celebración del contrato y el asegurador hubiera concluido el contrato por un premio mayor, la suma asegurada se reducirá en proporción al premio pagado.

En las demás hipótesis de agravación del riesgo previstas en la póliza, el asegurador podrá optar entre rescindir el contrato u ofrecer al asegurado el pago de una extraprima acorde al riesgo agravado.

En el caso analizado del COVID-19, tenemos que plantearnos antes que nada si los tomadores de seguros que resultaron positivos en cuanto a padecer el virus, deben denunciar esto a su asegurador de salud, a su asegurador de vida. Entiendo que no, 
pues como hemos dicho los agravamientos en materia de seguros de personas deben ser los previstos en la póliza, y los cambios en la salud del asegurado no son agravamiento del riesgo sino aumentos del riesgo que el asegurador tiene previstos desde el comienzo del contrato, pues prevé, en el riesgo asumido y el premio correspondiente, el envejecimiento de las personas y el avance de las enfermedades a medida que transcurre la vigencia del contrato.

Ahora bien, se trata obviamente de una alteración repentina y masiva, que objetivamente es un aumento de riesgo, pero entiendo que no por eso habilita en seguros de personas, la rescisión del contrato, por lo antedicho a la luz de nuestra ley.

Eso sin perder de vista que muchos países están decidiendo incluir al COVID-19 como enfermedad profesional, lo cual en Uruguay tendría un impacto relativo, y de estudio diferencial desde otra perspectiva económica, por ser un riesgo monopolizado en la entidad aseguradora estatal. Asimismo, porque la merma en la actividad laboral no debería hacer esperar un contagio masivo entre trabajadores.

En los seguros generales, entiendo que efectivamente es un riesgo agravado pues si el asegurador hubiera tenido en cuenta el riesgo de esta pandemia hubiera celebrado el contrato en otras condiciones o no lo hubiera celebrado.

Pero hoy no puede recurrir a la rescisión de los contratos vigentes pues los quince días de suspensión de cobertura previstos por nuestra ley, ya han transcurrido. Desde el 13 de marzo, fecha en que se decretó la especial cuarentena que vive Uruguay, la noticia del agravamiento llegó a conocimiento del asegurador, estando pues, los contratos que no hayan sido rescindidos en los quince días siguientes, vigentes en iguales condiciones que antes de la pandemia, por mandato de la disposición legal correspondiente.

Ahora bien, es obvio que el desequilibrio contractual existe, si el asegurador no tiene la exclusión por pandemia, objetivamente el contrato está desequilibrado pues el riesgo, en varias ramas de seguros, está agravado y el asegurador continúa recibiendo la misma contraprestación. Pues bien, al finalizar las vigencias, por norma anuales, de los contratos generales, de daño, el asegurador deberá estar atento para volver a recomponer el equilibrio contractual ajustando los premios, acorde a los riesgos actuales a asumir.

\section{Y ¿qué sucede si existe siniestro?}

Si en cambio, existe siniestro, de acuerdo al Art. 20 de nuestra ley de seguros, y el tomador o el asegurado omitieron denunciar el agravamiento del riesgo cubierto por el contrato, el asegurador queda liberado de su prestación, siempre que el siniestro haya sido provocado por hecho o circunstancias agravantes del riesgo que no fueron denunciadas.

O sea que no cualquier agravación del riesgo habilita al asegurador a no indemnizar el siniestro, sino que la no indemnización, - o no cumplimiento de la prestación, pues este artículo a diferencia del anterior, también aplica a los seguros de vida- solo ocurre si el siniestro fue "provocado" por la agravación y esta no había sido denunciada. 
Aquí existe un tema terminológico importante que puede dar lugar a cuestionamientos futuros, pues provocar no es igual a causar.

A primera vista, parecería que el legislador equivoca en este punto el concepto de agravación del riesgo, pues en el campo del derecho de seguros, la causalidad debe ser tomada con un alcance diferente al habitual, máxime en materia de agravación del riesgo.

Como expresa la doctrina, y más allá de las distintas posiciones, la causa en seguros es el antecedente que, además de haber resultado necesario en el caso concreto, en abstracto parece idóneo para producir por sí solo el evento. Resulta esencial el concepto de abstracción: la causa en derecho de seguros es una causa que debe ser idónea para producir el evento, aún en forma abstracta, es decir con separación o exclusión del sujeto, del caso concreto. Y máxime en el instituto de la agravación del riesgo donde aún el hecho del tercero puede configurar una agravación del riesgo del asegurado.

Ahora bien, el legislador no utiliza la palabra "causado" sino la palabra "provocado".

"Provocar", de acuerdo al Diccionario de la Real Academia Española significa "hacer que una cosa produzca otra como reacción o respuesta a ella" pero también "facilitar, ayudar, inducir". En cambio "causar" significa, "dicho de una causa, producir su efecto" y "ser causa, razón y motivo de que suceda algo".

Es en mi concepto claro, pues, que provocar puede aludir a una causa indirecta o coadyuvante, a un elemento que no tiene por qué ser la causa directa.

Esta interpretación parece la más adecuada al instituto de la agravación del riesgo en derecho de seguros: el riesgo se agrava independientemente de la ocurrencia o no del siniestro y si el legislador se inclina por exigir cierta relación entre la agravación y el siniestro no debe ser necesariamente la causa directa, puede ocurrir que el siniestro haya visto "provocado", es decir, favorecido, ayudado o facilitado por la agravación no denunciada, aunque esta no sea su causa directa ${ }^{8}$.

¿Qué sucede pues frente al COVID-19 si existe un siniestro?

Antes que nada, el asegurador deberá poder demostrar que se trata de un agravamiento del riesgo.

Es decir, por ejemplo, que la incidencia del virus ha hecho que las autoridades determinaran el cierre de negocios y que eso agravó el riesgo de pérdida de ganancias o lucro cesante para los comercios involucrados y asegurados. En ese caso, si esa circunstancia agravante provoca el siniestro, en el ejemplo provoca la pérdida de ganancias o lucro cesante, el asegurador podrá argumentar el agravamiento como eximente de su obligación de indemnizar.

Pero es claro que el asegurador deberá poder probar que el mentado virus constituye agravamiento de ese riesgo concreto que acaece, y que dicho agravamiento provoca el siniestro -en mi interpretación aún en forma coadyuvante- lo cual será un extre-

\footnotetext{
${ }^{8}$ Signorino Barbat, Andrea "Derecho de Seguros. Ley No 19.678 de Contrato de Seguros. Comentada y Anotada" THOMSON - Reuters - La Ley Uruguay - 2019.
} 
mo a analizar cobertura a cobertura y caso a caso, con las lógicas complejidades que esto implica.

¿Y qué sucede con la disminución del riesgo? Pues, en efecto nuestra Ley de seguros $\mathrm{N}^{\circ} 19.678$ prevé también la figura de la disminución del riesgo 9 .

En su Art. 17 establece que el tomador del seguro o el asegurado podrán, durante la vigencia del contrato, poner en conocimiento fehaciente del asegurador todas las circunstancias que disminuyan el riesgo y sean de tal naturaleza que, si hubieran sido conocidas por éste en el momento de la celebración del contrato, lo habría concluido en condiciones más favorables.

También, como en el agravamiento, la disminución debe compararse con las circunstancias al momento de la celebración del contrato, en este caso analizar si el asegurador, de haberlas conocido, habría celebrado el contrato en otras condiciones -en el caso de la disminución más favorables- por ejemplo, con un premio menor acorde al riesgo realmente asumido.

Es potestad del asegurado, no un deber como en el caso de agravamiento, poner estas circunstancias que disminuyen el riesgo en conocimiento del asegurador.

En dicho caso, estatuye la norma que el premio deberá adecuarse a la disminución del riesgo y si hubiere sido abonado, reducirse en la proporción correspondiente.

Asimismo, el asegurador tendrá derecho a rescindir unilateralmente el contrato dentro de los treinta días corridos siguientes a contar del día en que recibió la comunicación, en cuyo caso la rescisión producirá efectos transcurrido treinta días corridos de su notificación, entendemos notificación de la voluntad de rescindir al asegurado.

Es decir, que no es descabellado pensar que los asegurados podrían denunciar la disminución de sus riesgos, en algunas coberturas, ocurrida por causa del COVID-19 y así lograr una adecuación de sus premios en los contratos de seguros por ellos contratados, aún en los vigentes.

Esto siempre que demuestren que el mentado coronavirus ha disminuido sus riesgos o estos directamente se han tornado inexistentes.

Por ejemplo, en los seguros automotores, de daño propio o de responsabilidad civil o de accidentes personales, en los países donde estos no circulan, por no estar permitido, no habría riesgo de accidentes de tránsito con daños personales o materiales para el conductor, pasajero o terceros; probablemente la cobertura ante daño propio podría subsistir aunque disminuido su riesgo, si pensamos en situaciones como el derrumbe del techo del garaje donde se guarda el vehículo o circunstancias similares.

O pensemos en taxis, remises u otros vehículos de transporte de pasajeros o destinados al trabajo, a los que no se les permita circular o que no pueden ser utilizados para dichos fines por la inactividad provocada por el virus, en general son seguros que cobran un premio diferencial superior al del automotor de uso particular, por su mayor

9 Signorino, Andrea en op. cit. 
siniestralidad, y podrían reclamar ese ajuste del premio por disminución de su riesgo. Incluso, si circulan, como es el caso de Uruguay, la disminución en el volumen de trabajo disminuiría también su riesgo, aunque esto sea difícil de cuantificar.

Ahora bien, la contracara es que el asegurador como vimos puede, ante esta denuncia de la disminución del riesgo del asegurado, decidir rescindir el seguro, con el aspecto negativo de que dicho asegurado puede pretender legítimamente seguir asegurado, aunque con un ajuste del premio acorde a su riesgo actual, y debería ir en busca de otro seguro, y otro asegurador, en medio de tiempos de incertidumbre y dificultades en la contratación.

Por cierto, el asegurado también podría, ante dicha situación, decidir rescindir su contrato de seguro comunicándolo fehacientemente al asegurador con una antelación de un mes, como prevé el Art. 13 de la Ley $\mathrm{N}^{\circ}$ 19.678. No obstante, desde una visión de prevención, esto no resulta aconsejable salvo que el riesgo sea verdaderamente inexistente, para evaluar lo cual el asegurado no es un experto y debería asesorarse debidamente con el asegurador o con su asesor, corredor o agente.

\section{CONCLUYENDO}

El COVID-19 nos plantea múltiples desafíos actuales y futuros, cuando debamos adaptarnos a un mundo que seguramente no será igual al que conocimos. Esto nos abre un abanico de posibilidades de recrear nuestra forma de ver la vida y de ser optimistas de un progreso en los valores del ser humano.

Asimismo, planteará nuevos desafíos al mundo del trabajo y a la actividad económica mundial, de la cual el seguro es y seguirá siendo, pieza fundamental.

Creo pues, que el seguro debe ponerse a tono y acompañar estos cambios, esta evolución, como históricamente lo ha hecho.

Es una hora oportuna para que la actividad aseguradora gane visibilidad positiva ante la sociedad, dejando en claro que el seguro es necesario y útil ante las situaciones imprevistas. Finalmente, ese es el metier del asegurador: administrar con solvencia los riesgos de las personas y de las empresas.

No dudo que así lo hará, para bien del progreso de la nueva y reinventada, humanidad.

\section{BIBLIOGRAFÍA}

Código de Comercio de la República Oriental del Uruguay.

DuRÁn MÉNDEZ, S. "Imprevisión en contratos aleatorios: una revisión analítica a la teoría de la imprevisión bajo el Art. 868 del Código de Comercio". Revista de Derecho Privado, (55). Universidad de los Andes.

Fernández, De Almeida. Tesis doctoral Universidad de Salamanca “Alteración de las circunstancias y Revisión contractual", España, 2011. 
GAMARRA, Jorge. "Imprevisión y equivalencia contractual”, Cuadernos del Anuario de Derecho Civil Uruguayo, Fundación de Cultura Universitaria, Uruguay, 2006.

http://dx.doi.org/10.15425/redepriv.55.2016.04, Colombia, 2016.

Signorino Barbat, Andrea. Derecho de Seguros. Ley No 19.678 de Contrato de Seguros. Comentada y Anotada. Thomson-Reuters -La Ley Uruguay- Uruguay, 2019. 
